Cataloging and Classification Quarterly, 2010, Vol.48, No.2-3, p. 221-236.

ISSN: 0163-9374 (print) 1544-4554 (online)

doi: 10.1080/01639370903535726

http://www.tandf.co.uk/journals/copyright.asp

http://www.tandf.co.uk/journals/titles/01639374.asp

http://www.tandfonline.com/doi/full/10.1080/01639370903535726

(C) 2010 Taylor \& Francis Group

\title{
Program for Cooperative Cataloging: BIBCO Records: Analysis of Quality
}

\author{
MAGDA EL-SHERBINI \\ The Ohio State University
}

\begin{abstract}
The Program for Cooperative Cataloging (PCC) is an international program that brings together libraries that wish to participate in the creation and sharing of bibliographic records. These high quality records can be used by any library around the world without additional modification or change. Members of the cooperative adhere to a set of standards and practices that help eliminate extensive editing of records by participant libraries, thus allowing libraries to reduce the cost of cataloging. Even though the records submitted to the Online Computer Library Center (OCLC) database by PCC member institutions adhere to the established standards, some libraries continue to verify the quality of the access points in these records. Many libraries outsource this process to outside vendors who automatically check these records against the Library of Congress $(L C)$ Authority File. The purpose of this study is to examine the quality of the PCC records in light of the changes that were made by an authority control vendor. The author will analyze the changes made by the vendor to the PCC records and explain the reasons for those changes.
\end{abstract}

\section{INTRODUCTION}

The Library of Congress (LC) Program for Cooperative Cataloging (PCC) was established to improve the timely availability of bibliographic and authority records by cataloging more items, producing cataloging that is widely available for sharing and use by others, and performing cataloging in a more cost-effective manner. ${ }^{1}$ PCC provides training to members of the cooperative who adhere to a set of standards and practices that help eliminate extensive editing of records by participant libraries, thus allowing libraries to reduce the cost of cataloging. Even though the records submitted to the Online Computer Library Center (OCLC) database by PCC member institutions adhere to the established standards, some libraries continue to verify the quality of the access points in these records. Many other libraries outsource this process to outside vendors who automatically check these records against the Library of Congress Authority File. The purpose of this study is to examine the quality of the PCC records in light of the changes that were made by an authority control vendor. The author will analyze the changes made by the vendor to the PCC records and explain the reasons for those changes.

\section{BACKGROUND}


PCC is made up of four components: NACO (Name Authority Cooperative Program), SACO (Subject Authority Cooperative Program), BIBCO (Monographic Bibliographic Record Cooperative Program), and CONSER (Cooperative Online Serials Program). Through these four programs, member institutions contribute bibliographic records that follow mutually accepted cataloging standards. Before joining each program, potential member institutions participate in PCC training in order to assure consistency and accuracy of bibliographic records that will be produced by them.

The Monographic Bibliographic Record Cooperative Program (BIBCO) is an important component of PCC. BIBCO members have the responsibility for contributing full or core level bibliographic records to the program. As part of this process, members have to provide "complete authority work (both descriptive and subject), a national level call number (such as LC classification or NLM classification), and at least one subject access point drawn from nationally recognized thesauri such as $\mathrm{LCSH}, \mathrm{MeSH}$, etc., as appropriate." 2

Records submitted to the OCLC database by BIBCO contributors follow established rules and standards for authority work. These records are downloaded into local systems and many libraries submit these records to an authority control vendor to check them against the Library of Congress Authority File. Libraries use a vendor service instead of having their own copy catalogers check each individual record.

Libraries prepare a specific profile that is used by the vendor to check these records against the LC Authority File. The profile provides instruction to the vendor on what changes need to be made. Currently, The Ohio State University Library (OSUL) is using Backstage Library Works (BSLW) as their authority control vendor. ${ }^{3}$ BSLW provides name and subject authority control services based on the LC name and subject authority databases. The catalogers at OSUL do not check access points when they download records. However, they check the authority file when they are creating new records in the OCLC database. The OSUL policy is to depend on a commercial vendor to perform automated post-cataloging authority control without human intervention. This simplifies and accelerates the process of copy cataloging.

At the end of every month, the Cataloging Department produces a file of all records created by cataloging staff (original cataloging) and by other library units (copy cataloging). This file of records is then sent to BSLW for automated authority control processing according to a specific profile (e.g., check all access points, punctuation, tags, indicators, and spelling). After BSLW checks the bibliographic records against the LC Authority File, they correct the records automatically and provide OSUL with reports on unmatched headings, unrecognized subfields, and possible invalid tags.

\section{LITERATURE REVIEW}

PCC initiatives have been well documented in the library literature. ${ }^{4}$ The program Web site is an official source of information on PCC and its components (NACO, BIBCO, SACO, and CONSER). It includes documentation, as well as statistical and contact information. ${ }^{5}$ General information about the program can be found in "Becoming an Authority on Authority Control: An Annotated Bibliography of Resources." ${ }^{6}$ This bibliography includes monographs, articles and papers, electronic discussion groups, Web sites, training offered through NACO and SACO, and a summary of future trends in authority control. Riemer and Morgenroth discussed the increasing importance and the value of cooperative cataloging for librarians and library administrators. Their research focused on East Asian collections and PCC. ${ }^{7}$ Bowen also 
addressed the benefits and the cost effectiveness of the PCC core records by providing an explanation of the long-term value of the program. ${ }^{8}$ The PCC program now includes

participation by non-U.S. institutions, ${ }^{9}$ either through an "individual membership" to PCC or as a group through a "funnel."

Shrinking resources and budget reductions are among the major problems facing libraries today. Cataloging is among the most affected areas. Authority control in particular is often considered a labor intensive and expensive operation. In order to continue providing quality bibliographic records and to reduce the cost of processing, the PCC core record concept was introduced. ${ }^{10}$ The core record standard provides essential bibliographic elements based on acceptable standards that can be adapted without "modification" of the record at the local level. ${ }^{11}$ The core record concept was later expanded and adapted to include non-monographic materials. The Core Standard for Rare Books was adopted in 1999, but was met with some resistance from the rare book cataloging community. An investigation of this response was researched and analyzed in "Evidence of Application of the DCRB Core Standard in WorldCat and RLIN."12

Schuitema provided a lengthy introduction of the core bibliographic record and what it is, where the standard originates, and how the core level is different from the full level. ${ }^{13}$ She also addressed the issues that are associated with the implementation of the core record and examined some of the reasons libraries are implementing the core standards. Czeck, Icenhower, and Kellsey identified significant differences between records cataloged using OCLC core standards and PCC full standards, particularly in the occurrences of specific name and subject access points. ${ }^{14}$ This difference might have long term implications for user access and libraries should be alerted when they incorporate the core record in their copy cataloging procedures.

NACO, which was founded in 1979, has grown and expanded through the years and now includes international membership. In his article on the subject, Byrum pointed out that "The NACO model has changed over time to create more cost-effective and user-friendly policies and procedures to meet participants' needs. Increased recognition, especially by library administrators, of the value of authority control also encouraged NACO to flourish" (Abstract). ${ }^{15}$ In his article, he explained membership requirements, benefits to the participants, as well as the role of the Library of Congress in providing training and documentation and participation in the program through a "Funnel." Libraries that cannot join the NACO program directly have been creating NACO funnels to enable them to contribute records indirectly through another institution. Some of the reasons a library may not join the cooperative are a lack of cataloging expertise and resources or inability to meet the NACO minimum submission requirements. Larmore provided a step-by-step explanation of how to set up a NACO funnel among four academic and one state library in South Dakota. ${ }^{16}$ As a result of changing the objectives of contributing records to the NACO program, the University of Florida Libraries increased productivity in this area. ${ }^{17}$

Training catalogers on the NACO, BIBCO, SACO, and CONSER standards is essential to ensure the success of the program. Historical background on the PCC training and identifying the future needs in this area was discussed in "The Program for Cooperative Cataloging and Training for Catalogers." ${ }^{18}$ Calhoun and Boissonnas discussed the advantage of libraries joining PCC and cataloging according to BIBCO standards. ${ }^{19}$ In their discussion, they pointed out that PCC accomplishments included the establishment of shared standards for books, music, sound recordings, and audiovisual materials; simplifying and streamlining documentation; and implementing training programs. They pointed out that libraries should take advantage of the program and specifically emphasized the use of the core record concept that contains an 
accurate and standardized description and authorized access points. They also addressed the benefits of applying the core record in terms of cost effectiveness and enhanced user access.

The benefits of participating in PCC are numerous and recognized in the library community. A practical approach to reduce the cost of the creation of authoritative bibliographic records is to create a record based on acceptable standards once and share it several times. In her editorial column, Carter said: "Cooperative cataloging is a subject near and dear to my heart and one in which I fervently believe. This includes being a contributor to the collective databases of cataloging and not just a taker. During my years in technical service at the University of Pittsburgh I had the privilege of participating in CONSER policy development and supported the library's entry into NACO and Enhance." 20

Quality of the cataloging record and the criteria that are used to determine it was discussed extensively by Bade in his article "The Perfect Bibliographic Record: Platonic Ideal, Rhetorical Strategy of Nonsense?"21 Bade dismissed the concept of the "perfect record" and recommended a more pragmatic approach to the problem that would concentrate on matching the individual needs of a particular library with the corresponding set of data elements in the bibliographic record that would satisfy that institution's needs.

\section{METHODOLOGY}

To examine the quality of the PCC records in light of the changes that were made by the BSLW and to explain the reasons for those changes, the following steps were taken.

This author examined the file of records that were produced by OSUL catalogers in April 2009- This file was sent to BSLW for authority processing. The file consisted of 7,787 records and included records that were either created in the OCLC database by OSUL staff or were downloaded from the OCLC database.

Before sending this file to BSLW for post-authority control processing, the author used a Boolean search to separate the PCC records from non-PCC records. The "042" MARC 21 field was used to identify the PCC records. The result was a sample of 542 PCC records, about 7 percent of records downloaded in April. A printout was made of the PCC records, which were assigned a unique ID. The sample was then sent separately to BSLW for authority processing. The author did not distinguish between the PCC records created by OSUL staff and those created by other PCC participant libraries.

After the completion of authority processing, BSLW created several statistical reports that provided detail about the changes made to the PCC records. These reports were based on OSUL local requirements as outlined in the vendor profile. Before loading these records into the catalog, a copy of each record was made and given a unique ID.

The next step was to examine how many PCC records the vendor had corrected and which fields were changed. Criteria used to compare the records before and after authority processing were based on access points and fields of importance to OSUL. Series information was excluded and will need to be addressed in a separate study. These criteria are as follows:

Numbers and Codes

Library of Congress Control Number (010 field)

International Standard Book Number (020 field)

Library of Congress Call Number (050 field)

Local Call Numbers (090 field) Main Entries 
Main Entry-Personal Name (100 field)

Main Entry-Corporate Name (110 field)

Main Entry-Meeting Name (111 field)

Main Entry-Uniform Title (130 field)

Title and Title-Related Fields

Title Statement (for obvious misspellings) (245 field \$a)

Varying Form of Title (for obvious misspellings) (246 field)

Subject Access Fields

Subject Added Entry—Personal Name (600 field)

Subject Added Entry - Corporate Name (610 field)

Subject Added Entry—Meeting Name (611 field)

Subject Added Entry—Uniform Title (630 field)

Subject Added Entry-Topical Term (650 field)

Subject Added Entry-Geographic Name (651 field)

Index Term-Genre/Form (second indicator 0) (655 field)

Added Entries

Added Entry-Personal Name (700 field)

Added Entry - Corporate Name (710 field)

Added Entry-Meeting Name (711 field)

Added Entry-Uniform Title (730 field)

Criteria were then created to group the changes according to their importance to retrieval of records from the OSUL online catalog. Records were separated into two categories:

- Minor changes that do not affect the retrieval of records-punctuation, diacritics, and spaces.

- Major changes that impact the retrieval of records-incorrect indicators, incorrect or lack of subfield delimiters, incorrect tags, incorrect headings, and incorrect form of heading.

For the purpose of this study, statistical analysis takes into consideration the number of occurrences of errors, and not the number of records affected by the errors. Hence, there could be more errors in a certain area than there are records in the sample.

TABLE 1 Changes in Numbers and Codes Fields

\begin{tabular}{|l|c|c|c|}
\hline Numbers and Codes Fields & $\begin{array}{c}\text { Bibs with } \\
\text { This Field }\end{array}$ & $\begin{array}{c}\text { PCC Bibs } \\
\text { Changed }\end{array}$ & $\begin{array}{c}\text { Percent } \\
\text { Changed }\end{array}$ \\
\hline LC Control Number (010) & 273 & 272 & 99.6 \\
\hline ISBN (020) & 1089 & 0 & 0 \\
\hline LC Call Number (050) & 546 & 6 & 1.1 \\
\hline Locally Assigned LC-Type & 123 & 0 & 0 \\
\hline Call Number (090) & & & \\
\hline Total Numbers and Codes & 2332 & 280 & 12 \\
\hline Fields & & & \\
\hline
\end{tabular}


The printouts of records that were made before authority processing were compared to records returned from the vendor. All the changes that were made by the vendor were recorded on the printout. To avoid searching the Authority File (AF) for all the access points to determine if they had already been established, the author used the report that was generated by BSLW. This report showed the headings that did not match or were not yet established in the AF. These headings were then searched manually in the AF to determine the reasons for the lack of headings match. It was assumed that the original cataloger checked the AF to verify or establish headings before creating the records in OCLC, as this is required by the PCC BIBCO standards.

\section{RESULTS}

Changes in Numbers and Codes Fields (010, 020, 050, and 090)

Table 1 represents the most frequent changes that occurred in the LC Control Number (field 010) and the LC Call Number (field 050). Nearly all of the 010 fields were changed by the vendor to add a space between the subfield delimiter $(\$ a)$ and the LC Control Number, according to the OCLC Bibliographic Formats and Standards. ${ }^{22}$ In the 050 field, six errors were changed to correct spaces. It should be noted that there were 129 records with the 090 field (locally assigned LC-type call number). OSUL staff assigned local call numbers in the 090 field to adjust the Cutter number in certain classes (e.g., M, N, and P). However, the call numbers in the existing 050 fields were left untouched. There was no change in the International Standard Book Number (ISBN) (020 field). The changes in the Numbers and Codes fields were minor, because they did not affect the retrieval of records from the OSUL online catalog.

Changes in Main Entries (100, 110, 111, and 130 fields)

Table 2 shows the changes in the Main Entry that occurred during the authority control processing. The following is analysis of the changes in each Main Entry field:

TABLE 2 Changes in Main Entry Fields (100, 110, 111, and 130 Fields)

\begin{tabular}{|l|c|c|c|c|}
\hline Main Entry Fields & $\begin{array}{c}\text { Number of } \\
\text { Records that have } \\
\text { This Field }\end{array}$ & Total Match & $\begin{array}{c}\text { Total of Headings } \\
\text { Changed/Non } \\
\text { Match }\end{array}$ & $\begin{array}{c}\text { Percent of } \\
\text { Changes and Non } \\
\text { Match }\end{array}$ \\
\hline $\begin{array}{l}\text { Personal Name Main Entry } \\
(100)\end{array}$ & 359 & 167 & 192 & 53 \\
\hline $\begin{array}{l}\text { Corporate Name Main Entry } \\
(110)\end{array}$ & 14 & 8 & 6 & 75 \\
\hline $\begin{array}{l}\text { Meeting Name Main Entry } \\
(111)\end{array}$ & 7 & 5 & 2 & 29 \\
\hline Uniform titles (130) & 1 & 0 & 1 & 100 \\
\hline Total Main Entry Fields & 381 & 180 & 201 & 54 \\
\hline
\end{tabular}




\section{Changes in the Personal Name Main Entry (100 Field)}

About 53 percent (192 errors) of the Personal Name Main Entry (100 field) changed during authority processing. These changes can be grouped into two categories: minor changes noted in punctuation (153 errors), adding diacritics (18 errors), and deleting spaces (11 errors). Major changes occurred in indicators ( 2 errors), correcting tags ( 1 error), correcting subfields and subfield delimiters ( 3 errors). The largest number of changes was in punctuation (nearly 82 percent), where adding and deleting a period at the end of the heading was an issue. It should be noted that all of these changes were performed automatically by comparing the headings in the bibliographic records to the heading in the AF. Although there were small number of changes in tags, indicators, and subfields and subfield delimiters, these changes were important for the proper indexing and retrieval of the record.

The vendor reported that there were four headings that did not match the heading in the AF. Upon examination, it was determined that of the Personal Name Main Entries (100 field) that did not match, two were already found in the AF. These two records were created and added to the AF after the bibliographic records were input into OCLC. When the OSUL records were sent to the vendor for post-cataloging authority processing, these non-match headings were not in the AF. The other two names had not been established in the AF.

\section{Changes IN THE CoRPorate NAME MAIN ENTRY (110 FIELD)}

There were only fourteen fields in the sample set of records containing a 110 field. The vendor updated six fields to correct spaces (1 error) and punctuation (5 errors). Again, these changes were considered to be minor and do not effect the retrieval of the records.

TABLE 3 Changes in Title Information Fields (245, 246, and 240 Fields)

\begin{tabular}{|l|c|c|c|c|}
\hline & $\begin{array}{c}\text { Number of } \\
\text { Records that } \\
\text { have This } \\
\text { Field }\end{array}$ & Total Match & $\begin{array}{c}\text { Total of } \\
\text { Headings } \\
\text { Changed/Non } \\
\text { Match }\end{array}$ & $\begin{array}{c}\text { Percent of } \\
\text { Non Match }\end{array}$ \\
\hline Title (245) & 542 & 476 & 66 & 12.2 \\
\hline Other Title Information (246) & 125 & 125 & 0 & 0 \\
\hline Total Title Information Fields & 667 & 601 & 66 & 10 \\
\hline
\end{tabular}

\section{Changes in the Meeting Name Main Entry (111 Field)}

There were seven fields in the sample records for the Meeting Name Main Entry (111 field) and two errors were changed to correct punctuation.

\section{ChANGES IN THE UNIFORM TITLES (130 FIELDS)}

There was one Uniform Title main entry (130 field) in the sample that was reported by the vendor as a non-match. An examination of this heading revealed that it was not established in the AF. 
Changes in Title and Title-Related Fields (245, 246, Fields)

In examining the Title Fields (245 field) it was determined that 66 titles (12\%) were changed (see Table 3). Of those, 48 errors (about 67 percent) were changed to correct spaces, six errors were corrected for misspelling, eight errors were corrected for non-filing indicators, and four errors were changed in the subfields and subneld delimiters. These changes in the title field were all done by the vendor through an automated process without human intervention. Searching these titles against the OCLC master records revealed that the records in OCLC remained incorrect. Although there were not many misspellings and non-filling indicators, these were important to correct because their accuracy has an impact on users' ability to search and retrieve records. There were no changes in the 246 field and all the title information in this field was correct.

Changes in the Subject Access Fields (600, 610, 611, 630, 650, 651, 655)

Table 4 shows the changes in the Subject Access that were made during the authority control processing. The following is analysis of the changes in each Subject Access field.

TABLE 4 Changes in Subject Access Fields (600, 610, 611, 650, 651, and 655 Fields)

\begin{tabular}{|l|c|c|c|c|}
\hline & $\begin{array}{c}\text { Number of } \\
\text { Records that } \\
\text { have This } \\
\text { Field }\end{array}$ & Total Match & $\begin{array}{c}\text { Total of } \\
\text { Headings } \\
\text { Changed/Non } \\
\text { Match }\end{array}$ & $\begin{array}{c}\text { Percent of } \\
\text { Non Match }\end{array}$ \\
\hline $\begin{array}{l}\text { Personal Name Subject Heading } \\
(600)\end{array}$ & 117 & 77 & 40 & 34 \\
\hline $\begin{array}{l}\text { Corporate Name Subject Headings } \\
(610)\end{array}$ & 28 & 15 & 13 & 46 \\
\hline $\begin{array}{l}\text { Meeting Name Subject Headings } \\
(611)\end{array}$ & 0 & 0 & 0 & 0 \\
\hline Subject Heading Uniform Title (630) & 15 & 9 & 6 & 40 \\
\hline Topical Subject Headings (650) & 1422 & 629 & 793 & 56 \\
\hline Subject Headings Geographic (651) & 128 & 65 & 63 & 49 \\
\hline Genre Headings (655) & 42 & 17 & 25 & 60 \\
\hline Total Subject Access Fields & 1752 & 802 & 940 & 54 \\
\hline
\end{tabular}

\section{Changes in the Personal Name SubJect Heading (600 Field)}

There were 117 Personal Name Subject Headings in the sample records and forty (34 percent) were updated as a result of authority processing. Most of these changes were to correct punctuation ( 24 errors), subfield and subfield delimiters ( 1 error), indicators ( 1 error), and adding diacritics (12 errors). Although correcting punctuation and adding diacritics are considered minor changes, correcting indicators and subfields and subfield delimiters are important for proper indexing and retrieval of records. There were also two fields that were reported by the vendor as non-match. Both were searched in the AF and already established. 
They were reported as non-matches because they had a form as a subdivision; however, for the purposes of this study, they are not considered true errors.

Changes in the Corporate Name Subject Headings (610 Field)

There were 28 fields that include the Corporate Name Subject Headings (610 field) in the sample records; thirteen fields (46\%) were changed to correct punctuation (11 errors) and diacritics (2 errors).

\section{Changes IN THE SubJeCt HeAding Uniform Title (630 Field)}

In comparing this field before and after authority processing, six fields out of fifteen (40 percent) were reported by the vendor as non-matching. Upon examination, it was determined that these six headings were in the same bibliographic record (OCLC \# 318988782). They were actually two different headings with multiple form subdivisions; again, these are not considered errors.

\section{Changes IN THE Topical SubJect Headings (650 FIELD)}

There were numerous changes in the 650 Topical Subject Heading field, as 793 errors (56 percent) were corrected for spaces (255 errors), punctuation (447 errors), changes in subfields delimiters from " $x$ " to " $v "$ and vice versa (59 errors), changes in tags (14 errors) and indicators (11 errors). Changing subfield and subfield delimiters, tags, and indicators were important since they affect the meaning of the term and they have an impact on the users' ability to find the record.

There were 7 fields that were reported by the vendor as non-match headings in the AF. Of these, 5 were major errors as defined by the parameters of this study, including two MARC tagging errors, and three errors in subject heading assignment.

\section{Changes IN THE SubJect Headings GeOgRaphic (651 FIELD)}

There were 128 Geographic Subject Headings. Of this number, 63 fields were changed to correct punctuation (31 errors), spaces (27 errors), and subfield and subfield delimiters ( 7 errors).

\section{Changes IN THE GenRe HeAdings (655)}

There were 25 errors that were changed. In most cases, the indicators were changed from "7" to "0" in 14 fields. Eleven headings (two of them were repeated three times) were reported as non-match by the vendor. In checking these headings in the AF, it was discovered that they had already been established, but two of them had typos and were not corrected by the cataloger locally or in the OCLC master record. ${ }^{23}$

Changes in Added Entries Fields (700, 710, 711, and 730)

Table 5 provides information on changes in Added Entries. The following is an analysis 
of the changes in each Added Entry field.

\section{Changes in the Personal Name AdDEd EntRy (700 Field)}

Out of 400 Personal Name Added Entry fields included in the sample records, 182 fields (46\%) were changed by the vendor. Most changes in this field occurred in punctuation (78 errors), adding diacritics ( 29 errors), deleting spaces (63 errors), correcting indicators (5 errors), and correcting subfield delimiters (4 errors). The vendor reported that there were 3 headings that were not matched in the AF. After searching these headings in, it was determined that one already existed in the AF, one was not found, and the third was ambiguous.

TABLE 5 Changes in Added Entries Fields (700, 710, 711, and 730 Fields)

\begin{tabular}{|l|c|c|c|c|}
\hline & $\begin{array}{c}\text { Number } \\
\text { of } \\
\text { Records } \\
\text { that have } \\
\text { This Field }\end{array}$ & $\begin{array}{c}\text { Total } \\
\text { Match }\end{array}$ & $\begin{array}{c}\text { Total of } \\
\text { Headings } \\
\text { Changed/ } \\
\text { Non } \\
\text { Match }\end{array}$ & $\begin{array}{c}\text { Percent of } \\
\text { Non } \\
\text { Match }\end{array}$ \\
\hline $\begin{array}{l}\text { Personal Name Added Entry } \\
\text { (700) }\end{array}$ & 400 & 218 & 182 & 46 \\
\hline $\begin{array}{l}\text { Corporate Name Added Entry } \\
\text { (710) }\end{array}$ & 128 & 32 & 96 & 75 \\
\hline $\begin{array}{l}\text { Meeting Name Added Entry } \\
\text { (711) }\end{array}$ & 1 & 1 & 0 & 0 \\
\hline $\begin{array}{l}\text { Added Entries Uniform Titles } \\
\text { (730) }\end{array}$ & 4 & 0 & 4 & 100 \\
\hline Total Added Entries Fields & 533 & 251 & 282 & 53 \\
\hline
\end{tabular}

\section{Changes IN THE CoRporate NAME AdDed EnTRy (710 Field)}

There were 128 Corporate Name Added Entries in the sample records (710 field) and about three quarters of these fields changed. The major changes that occurred in this field were due to corrections in punctuation ( 65 errors), diacritics ( 22 errors), indicators (1 error), and subfield and subfield delimiters ( 2 errors). In this field, there were 6 headings that were reported by the vendor not to match the AF. In investigating these headings it was determined that only one heading was already added to the AF and one had not been established yet. The other headings were problems. ${ }^{24}$

\section{ChANGES IN THE MEETing NAME AdDED ENTRY (711 FieLD)}

There was only one Meeting Name Added Entry and it matched the AF.

\section{ChANGES IN THE AdDED ENTRIES UNIFORM TITLES (730 FieLDS)}

There were a total of four Uniform Title added entries in the sample records and the vendor reported all of them as non-match headings. An examination of these headings revealed 
that none of them had been established in the AF. These headings should have been established as part of the PCC standard requirement.

\section{DISCUSSION AND CONCLUSION}

A detailed examination of changes made by Backstage Library Works (BSLW) to the PCC records submitted at the end of April 2009 by the OSUL revealed certain patterns of errors and omissions. In measuring and assessing the quality of the PCC records in terms of the authority work and the accuracy of information, it was determined that the PCC records contain errors ranging from simple to serious. Some of these, such as adding or deleting spaces (355 errors), adding or deleting diacritics (133 errors) or punctuation marks (1,098 errors) are merely cosmetic. These changes have little or no impact on the user's ability to search and find the record in the online catalog. Other changes, such as correcting tags (14 errors), correcting indicators (29 errors), correcting subfields and subfield delimiters (76 errors), and spelling (6 errors), will affect the ability to search and retrieve these records.

There were 381 fields among the sample records that contained Main Entries. Table 6 shows the distribution of the 201 errors that were corrected during the authority processing (about 53 percent). Most errors (80 percent) corrected by the vendor occurred in the punctuation area, 9 percent diacritics, and 6 percent correcting spaces. A typical example involved adding or deleting a "." at the end of the field and deleting spaces. This type of error does not affect access to the record in the OSUL online catalog.

There were relatively few errors in indicators, subfields, subfield codes, and tags. Although the number of errors in these areas was not significant, they need to be corrected because they will affect indexing and retrieval of records. Unfortunately these records will remain incorrect in the OCLC database, but will be corrected at those libraries that have postcataloging processing done by a vendor service.

Five headings in the Main Entries areas were reported as "not found in the Authority File" by the vendor at the time of the authority control processing. Two of these headings were found during this study. This indicates a lack of synchronization between the time the bibliographic record is created and the time the authority record is added to the AF. The problem may also result from the BIBCO cataloger not being a member of NACO, and not being able to contribute to NACO.

TABLE 6 Distribution of Changes in Main Entries

\begin{tabular}{|l|c|c|}
\hline Type of Changes & $\begin{array}{c}\text { Number of the } \\
\text { Changes }\end{array}$ & Percent of Changes \\
\hline Punctuation & 160 & 80 \\
\hline Space & 12 & 6 \\
\hline Diacritics & 18 & 9 \\
\hline Subfield and subfield delimiters & 3 & 1.5 \\
\hline Indicators & 2 & 1 \\
\hline Tag & 1 & .5 \\
\hline Non-matched headings & 5 & 2.5 \\
\hline Total changes & 201 & 100 \\
\hline
\end{tabular}


TABLE 7 Distribution of Changes in the Subject Areas

\begin{tabular}{|l|c|c|}
\hline Type of Changes & $\begin{array}{c}\text { Number of the } \\
\text { Changes }\end{array}$ & Percent of Changes \\
\hline Punctuation & 515 & 55 \\
\hline Space & 280 & 30 \\
\hline Diacritics & 13 & 1.5 \\
\hline Subfield and subfield delimiters & 67 & 7 \\
\hline Indicators & 26 & 3 \\
\hline Tag & 13 & 1.4 \\
\hline Non-matched headings & 26 & 3 \\
\hline Total changes & 940 & 100 \\
\hline
\end{tabular}

There were a total of 1,742 subject fields among the sample records and about 54 percent (940 errors) were changed. Table 7 shows that the largest percentage of changes occurred in punctuation (55 percent), followed by correcting spaces (30 percent), and adding diacritics (1 percent). The major problems in the subject area occurred in correcting subfields and subfield delimiters ( 7 percent) followed by changing indicators ( 3 percent), and correcting tags (1 percent). Although the number of major changes was relatively small, correcting these errors is important for proper indexing and accessing of the records in the OSUL online catalog.

There were 26 headings ( 3 percent) reported as "non-matched" by the vendor, especially in Personal Name Subject Headings, Subject Headings Uniform Title, and the Genre Headings. Other problems that caused the headings to result in a non-match were due to mis-tagging, freefloating subdivisions, form as a subdivision (\$v), mis-constructing the subject heading, and not following the cross-references guide. In some cases the heading was not established in the Authority File at the time of authority control process. These problems require skilled catalogers to investigate them and correct them manually. According to the OSUL profile with the BSLW, the authority control vendor was only able to correct obvious errors that can be detected by the software.

In the Added Entries fields, there were 282 errors that were changed by the vendor. Table 8 shows the distribution of these changes. Most errors occurred in punctuation (51 percent), followed by correcting spaces (22 percent) and diacritics (18 percent). Changing indicators and adding subfields and subfield delimiters represent only two percent. The percentage of non-matched headings was very small. Only four percent were not in the AF at the time of authority control processing.

Although the number of fields corrected by the BSLW in the sample record was substantial, this study reveals that majority of these would not affect indexing or retrieval of these records from the OSUL online catalog. These include punctuation, diacritics and spaces. These errors were corrected by the vendor for the client institution, but will not be corrected in the master record in OCLC. This type of error is not significant enough to be corrected inhouse, if the vendor service was not used. 
TABLE 8 Distribution of Changes in Added Entries

\begin{tabular}{|l|c|c|}
\hline Type of Changes & $\begin{array}{c}\text { Number of the } \\
\text { Changes }\end{array}$ & Percent of Changes \\
\hline Punctuation & 143 & 51 \\
\hline Space & 63 & 22 \\
\hline Diacritics & 51 & 18 \\
\hline Subfield and subfield delimiters & 6 & 2 \\
\hline Indicators & 6 & 2 \\
\hline Tag & 0 & 4 \\
\hline Non-matched headings & 13 & 100 \\
\hline Total changes & 282 & \\
\hline
\end{tabular}

There is a smaller subset of errors that were corrected by BSLW that are more important, as they would have an impact on access and retrieval of records. These errors involve indicators, subfields and subfield delimiters, tags, spelling errors, and form of subject heading. Although there were a total number of 244 errors reported, this does not mean that so many records were affected. There were instances of multiple errors that were corrected in a single record, and the total number of records affected by this is substantially smaller than the statistical table indicates.

In conclusion, the quality of the PCC-produced bibliographic records is high, as defined by the parameters of this study. The vast majority of the errors noted in the statistical tables were not substantial. The relatively small number of major errors occurred in the subfields and subfield delimiters, indicators, and tags. The vendor service used by the OSUL is good at identifying and correcting those records that contain major errors that have an impact on the accessibility of records in the online catalog. In the process, the vendor identifies and corrects other errors that have little or no bearing on the retrieval of records. Most of the errors in the sample records occurred at the time of original production of the catalog record. As PCC continues to develop and grow its cooperative cataloging program, it could consider offering continuing education or training of original catalogers involved in the program.

\section{NOTES}

1. PCC Web site, http://www.loc.gov/catdir/pcc/ (accessed November 23, 2009).

2. BIBCO Web site, http://www.loc.gov/catdir/pcc/bibco/bibcopara.html (accessed November 23, 2009).

3. Backstage Library Works Web site. http://www.bslw.com/authority_control.htmKaccessed November 23, 2009).

4. Carol Mandel, "Cooperative Cataloging: Models, Issues, Prospects," Advances in Librarianship 16 (1992): 33-82.

5. PCC web site, http://www.loc.gov/catdir/pcc/ (accessed November 23, 2009).

6. Robert E. Wolverton, "Becoming an Authority on Authority Control: An Annotated Bibliography of Resources," Library Resources \& Technical Services 50, no. 1 (2006): 31^1.

7. J. J. Riemer and K. Morgenroth, "Hang Together or Hang Separately: The Cooperative Authority Work Component of NACO," Cataloging \& Classification Quarterly 17, no. 3-4 (1993): 127-161.

8. Jennifer B. Bowen, "Creating a Culture of Cooperation." Cataloging \& Classification Quarterly 26, no. 3 (December 31, 1998): 73-85.

9. Anthony R. D. Franks and Ana Cristan, "International Cooperation in the Program for Cooperative Cataloging: Present and Prospects." Cataloging \& Classification Quarterly 30, no. 4 (2000): 37.

10. The PCC Core Records Web site, http://www.loc.gov/catdir/pcc/bibco/coreintro.html (accessed November 23, 2009). 
11. S. E. Thomas, "The Core Bibliographic Record and the Program for Cooperative Cataloging," Cataloging \& Classification Quarterly 21, no. 3-4 (1996): 91-108.

12. Winslow Lundy, "Use and Perception of the DCRB Core Standard." Library Resources \& Technical Services 47, no. 1 (January 2003): 16-27.

13. Joan E. Schuitema, "Demystifying Core Records in Today's Changing Catalogs," Cataloging \& Classification Quarterly 26, no. 3 (December 31, 1998): 57-71.

14. Rita L. H. Czeck. Elizabeth Icenhower, and Charlene Kellsey, "PCC Core Records Versus PCC Full

Records: Differences in Access?" Cataloging \& Classification Quarterly 29, no. 3 (2000): 81-92

15. John D. Byrum Jr., "NACO: A Cooperative Model for Building and Maintaining a Shared Name

Authority Database," Cataloging \& Classification Quarterly 38, no. 3-4 (2004): 237-249.

16. Dustin P. Larmore, "A New Kid on the Block: The Start of a NACO Funnel Project and What Is

Needed to Start Your Own," Cataloging \& Classification Quarterly 42, no. 2 (2006): 75-81.

17. Betsy Simpson, and Priscilla Williams, "Growing a NACO Program: Ingredients for Success."

Cataloging \& Classification Quarterly 40, no. 1 (2005): 123-132.

18. Carol G. Hixson and William A. Garrison, "The Program for Cooperative Cataloging and Training for Catalogers," Cataloging \& Classification Quarterly 34, no. 3 (2002): 355.

19. Karen S. Calhoun, and Christian M. Boissonnas, "BIBCO: A Winning Proposition for Library Users and Staff," Library Acquisitions 22, no. 3 (1998): 251-255.

20. Ruth C. Carter, "Cooperative Cataloging." Cataloging \& Classification Quarterly 30, no. 4 (2000): 1.

21. David Bade, "The Perfect Bibliographic Record: Platonic Ideal, Rhetorical Strategy or Nonsense," Cataloging \& Classification Quarterly 46, no. 1 (2008): 109-133.

22. OCLC Bibliographic Formats and Standards-LC Control Number, http://www.oclc.org/ bibformats/en/Oxx/OlO.shtm

23. See "Christion fiction" in the OCLC record numbers 10385060 and "Science ficton" in the 6774710).

24. One record "Standard Publishing Company" has two possibilities, Standard Publishing Co. (Quincy, Mass) and Standard Publishing Company (Cincinnati, Ohio). Based on the OCLC record cited, the Cincinnati, Ohio entry is the correct one (OCLC record number (320363906). Another heading with a problem was the "American Academy of Pediatrics. \$b Section on Home Care." "American Academy of Pediatrics" is in the AF, but $\$ \mathrm{~b}$ "Section on Home Care" is not; however, there is \$b "Section on Home Health Care" in the AF. It is possible that the word "Health" was accidentally omitted from the beading. The third heading that was a problem is "Universidad de los Andes (Bogota, Columbia). \$b Facultad de Ciencas Sociates. \$b Departamento de Languajes y Estudios Socioculturales." This heading was in the AF but the last $\$ \mathrm{~b}$ "Departamento de Languajes y Estudios Socioculturales" was not (OCLC record number 220868279). The fourth heading, "Sbanxi Sheng (China). \$b Guo tu zi yuan ting" had not been established in the AF. However, "Shaanxi Sheng (China)" was found in the AF while browsing. This heading needs more investigation by an expert cataloger to determine the correct form of the name (OCLC record number 60635282). 